\title{
Respiration of Pseudomonas fluorescens as a function of intracellular substrate concentration
}

\author{
Alexander G. Dorofeyev, ${ }^{1}$ Michael J. Bazin, ${ }^{2}$ James M. Lynch ${ }^{3}$ \\ and Nicolai S. Panikov ${ }^{1}$ \\ Author for correspondence: Nicolai S. Panikov. Tel: +79513511 71. Fax: +7951356530. \\ e-mail: panikov@imbran.msk.su
}

\author{
1 Institute of Microbiology, \\ Russian Academy of \\ Sciences, Prospect 60-Let \\ Octyabrya 7/2, 117811 \\ Moscow, Russian \\ Federation \\ 2 Department of \\ Microbiology, King's \\ College London, Campden \\ Hill Road, London \\ W8 7AH, UK \\ 3 School of Biological \\ Sciences, University of \\ Surrey, Guildford, Surrey \\ GU2 5XH, UK
}

\begin{abstract}
A kinetic method to measure the intracellular concentration of respiratory substrates in short-term starvation-enrichment experiments is proposed. Samples of bacterial suspension from steady-state chemostat cultures were subjected to $25 \mathrm{~min}$ starvation, followed by pulse addition of $\left[{ }^{14} \mathrm{C}\right]$ glucose. Residual substrate utilization rates and respiration rates (uptake of dissolved $\mathrm{O}_{2}$ ) before and after amendment were recorded. Increases in pool sizes $(\Delta L)$ during transients were calculated on the basis of $\mathrm{C}$ balance. The dependence of respiration rate $q_{\text {rosp }}$ on $\Delta L$ was found to obey modified Michaelis-Menten kinetics: $q_{\text {resp }}=Q_{\text {resp }}(\hat{L}+\Delta L) /\left(K_{L}+\hat{L}+\Delta L\right)\left[Q_{\text {resp }}\right.$ is maximal respiration rate (29.1 mmol $\mathrm{O}_{2} \mathrm{~h}^{-1}$ per $\mathrm{g}$ biomass $\mathrm{C}$ ), $K_{\mathrm{L}}=12.14 \mathrm{mg} \mathrm{C}$ per $\mathrm{g}$ biomass $\mathrm{C}$, where $\hat{L}$ is the absolute value of the pool size before amendment. Direct chemical determination of $\hat{L}$ in cold TCA extracts revealed two fractions. The first fraction was mobile and showed a close correlation with both respiration and $L$. The second, 'stable', fraction did not correlate with respiration dynamics and was interpreted as material formed artifactually by acid degradation of polymeric cell components.
\end{abstract}

Keywords: growth kinetics, structured models, starvation-enrichment, respiration, carbon balance

\section{INTRODUCTION}

Numerous kinetic studies have been devoted to the effects of substrate concentration on the rate of microbial growth and metabolism (Pirt, 1975). The most commonly employed relationship between specific growth rate $(\mu)$ and substrate concentration $(s)$ is probably the equation of Monod (1942):

$\mu=\mu_{\mathrm{m}} \frac{s}{K_{\mathrm{s}}+s}$

where $\mu_{\mathrm{m}}$ is the maximal value of $\mu$ and $K_{\mathrm{s}}$ is the saturation constant, interpreted as a measure of biomass affinity to substrate. Both parameters are usually assumed to be constant with respect to a particular microbial species and a particular substrate.

However, it is now clear that the behaviour of microbial populations depends not only on the instantaneous environmental conditions (including substrate concentration in the medium), but also on the past history of the culture and its physiological state. This is to say, cell composition, concentrations of activators and inhibitors, the range of metabolic activities, etc., vary in response to present and past environmental conditions, and these will affect factors such as growth rate. Hence there is no unique set of values for $\mu_{\mathrm{m}}$ and $K_{\mathrm{s}}$ for a particular microbial species, since potential growth rate and substrate affinity are not constant. Therefore, there is no unique elementary mathematical expression describing the dependence of growth rate on substrate concentration. A number of so-called structured models have been developed which consider $\mu$ to depend on internal cellular variables $\mathrm{C}_{1}, \mathrm{C}_{2}, \ldots, \mathrm{C}_{n}$ such that

$\mu=f\left[s, \mathrm{C}_{1}, \mathrm{C}_{2}, \ldots, \mathrm{C}_{n}\right]$

where $\mathrm{C}_{1}, \mathrm{C}_{2}, \ldots, \mathrm{C}_{n}$ are cell components such as enzymes, proteins, ribosomes, reserve compounds and metabolic intermediates. These structured models can simulate the complex behaviour of microbial populations (Powell, 1967; Fredrickson, 1976; Domach et al., 1984; Jeong et al., 1990; Panikov, 1991), but they are often complex and the variables they employ often cannot be identified or measured experimentally. 


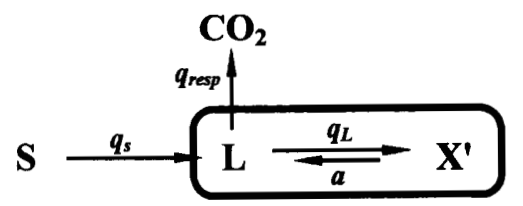

Fig. 1. Flow diagram of substrate $(S$, the source of carbon and energy) consumption and conversion into polymeric cell components $\left(X^{\prime}\right)$ via intracellular low-molecular-mass metabolites $(L)$. Arrows indicate specific rates of transport $\left(q_{s}\right)$, biosynthesis $\left(q_{L}\right)$, respiration $\left(q_{\text {resp }}\right)$ and turnover $(a)$.

Recently, we proposed and tested (Panikov, 1991, 1995; Dorofeyev \& Panikov, 1992) a relatively simple structured model, the 'synthetic chemostat model' (SCM), which includes versions of several chemostat models (Monod, 1950; Herbert, 1958; Powell, 1967, 1969; Ierusalimsky, 1967; Nyholm, 1976; Guthke \& Knorre, 1980 ) as elements. In the SCM, cell growth is represented by the scheme shown in Fig. 1. This model describes the conversion of an exosubstrate $S$ (exemplified by a source of carbon and energy) into polymeric cell components $\mathrm{X}^{\prime}$ via low-molecular-mass metabolites, $\mathrm{L}$. Intracellular fluxes $q_{\mathrm{L}}$ and $q_{\text {resp }}$ are assumed to be functions of $\mathrm{L}$ concentration. $\mathrm{L}$ metabolites are biochemically welldefined and include amino acids, nucleotides and carboxylic acids. However, it has so far not been possible to estimate the integrated concentration of the metabolites in vivo and relate them quantitatively to the rates of metabolic reactions.

The objective of the present study was to test several direct and indirect approaches to quantify the effects of intracellular substrate concentration on the rates of microbial growth and respiration.

\section{THEORY}

Symbols and units. These are as follows unless otherwise stated:

$s \quad$ Substrate concentration in the culture fluid (mg C ${ }^{-1}$ )

$s_{\mathrm{r}} \quad$ Substrate concentration in medium feed (mg C $~^{-1}$ )

$x \quad$ Biomass concentration (mg biomass $\mathrm{Cl}^{-1}$ )

$L \quad$ Intracellular content of substrate [g C (g biomass $\mathrm{C})^{-1}$ ]

$l \quad$ Intracellular substrate concentration per culture volume ( $=L x, \mathrm{mg} \mathrm{C}^{-1}$ )

$X^{\prime} \quad$ Content of polymeric cell components [g C $(\mathrm{g} \text { biomass } \mathrm{C})^{-1}$ ]

$x^{\prime} \quad$ Concentration of polymeric cell components per culture volume $\left(=X^{\prime} x, \mathrm{mg} \mathrm{Cl}^{-1}\right)$

$p \quad \mathrm{CO}_{2}$ concentration in headspace air (mg CO $2-\mathrm{C}$ or $\mathrm{mmol} \mathrm{CO}_{2}$ per 1 culture fluid) o Dissolved $\mathrm{O}_{2}$ concentration $\left(\mathrm{mmol}^{-1}\right)$

$q_{\mathrm{s}} \quad$ Specific rate of exosubstrate uptake $\left[\mathrm{g} \mathrm{C} \mathrm{h}^{-1}\right.$ (g biomass $\mathrm{C})^{-1}$ ]

$q_{\mathrm{L}} \quad$ Specific rate of $\mathrm{X}^{\prime}$ synthesis $\left[\mathrm{g} \mathrm{C} \mathrm{h}^{-1}\right.$ (g biomass $\mathrm{C})^{-1}$ ]

$q_{\text {resp }}$ Specific respiration rate $\left[\mathrm{g} \mathrm{CO}_{2}-\mathrm{C} \mathrm{h}^{-1}\right.$ (g biomass C) ${ }^{-1}$ or $\mathrm{mmol} \mathrm{O}_{2} \mathrm{~h}^{-1}$ (g biomass $\mathrm{C})^{-1}$ ]

$q_{\text {resp }}^{\prime}$ Specific rate of endogenous respiration (i.e. respiration of starved cells)

a Specific decay rate of cell polymeric components $\left(\mathrm{h}^{-1}\right)$

$Q \quad$ Stoichiometric ratio $\left(q_{\mathrm{L}}+q_{\text {resp }}\right) / q_{\text {resp }}$ (dimensionless)

$\mathrm{Y}_{\mathrm{s} / \mathrm{p}} \quad$ Stoichiometric parameter relating substrate uptake and oxidation [g glucose- $\mathrm{C}$ $\left(\mathrm{g} \mathrm{CO}_{2}-\mathrm{C}\right)^{-1}$ ]

$t \quad$ Time (h)

D Chemostat dilution rate $\left(\mathrm{h}^{-1}\right)$

The sources and sinks of variables are described by the following set of differential equations:

$\frac{\mathrm{d} s}{\mathrm{~d} t}=D\left(s_{\mathrm{r}}-s\right)-q_{\mathrm{s}} x$
$\frac{\mathrm{d} l}{\mathrm{~d} t}=q_{\mathrm{s}} x-q_{\mathrm{resp}} x-q_{\mathrm{L}} x+a^{\prime} x-D l$
$\frac{\mathrm{d} x^{\prime}}{\mathrm{d} t}=q_{\mathrm{L}} x-a^{\prime} x-D^{\prime} x$
$\frac{\mathrm{d} p}{\mathrm{~d} t}=q_{\mathrm{resp}} x-D p$
$\frac{\mathrm{d} x}{\mathrm{~d} t}=\frac{\mathrm{d} l}{\mathrm{~d} t}+\frac{\mathrm{d} x^{\prime}}{\mathrm{d} t}=(\mu-D) x, \quad \mu=q_{\mathrm{s}}-q_{\mathrm{resp}}$

Here we use identical units for all variables $\left(\mathrm{mg} \mathrm{C}^{-1}\right)$ and for the sake of simplicity assume that the rate of gas replacement in the fermenter headspace (eqn 6) is equal to the dilution rate, $D$, of the culture. Then the conservation condition is simple:

$\frac{\mathrm{d} s}{\mathrm{~d} t}+\frac{\mathrm{d} l}{\mathrm{~d} t}+\frac{\mathrm{d} x^{\prime}}{\mathrm{d} t}+\frac{\mathrm{d} p}{\mathrm{~d} t}=\frac{\mathrm{d} s}{\mathrm{~d} t}+\frac{\mathrm{d} x}{\mathrm{~d} t}+\frac{\mathrm{d} p}{\mathrm{~d} t}=0$

Intracellular substrate concentration, represented by variable $l$, is expressed as mg $C$ per unit culture volume (eqn 4). The intracellular substrate in terms of fraction of total biomass carbon, $L$ ( $\mathrm{g} \mathrm{C}$ per $\mathrm{g}$ biomass $\mathrm{C}$ ), is given by

$$
\begin{aligned}
& \frac{\mathrm{d} L}{\mathrm{~d} t}=q_{\mathrm{s}}-q_{\mathrm{resp}}-q_{\mathrm{L}}+\alpha(1-L)-\mu L(9) \\
& \text { Change Transport Oxidation Incorporation Input from Dilution due }
\end{aligned}
$$

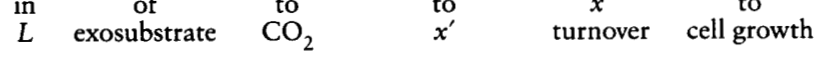

By introducing the stoichiometric parameter $\Theta=$ 
$\left(q_{\mathrm{L}}+q_{\text {resp }}\right) / q_{\text {resp }}$, we can simplify eqn (9) in the following way:

$\frac{\mathrm{d} L}{\mathrm{~d} t}=q_{\mathrm{s}}-\Theta q_{\mathrm{resp}}+a(1-L)-\mu L$

Under steady-state conditions in chemostat culture $\mu=$ $D$ and $\mathrm{d} L / \mathrm{d} t=0$, so the steady-state value $\tilde{L}$ may be calculated from the relationship

$\begin{aligned} q_{\mathrm{s}}+a(1+\tilde{L})-\Theta q_{\mathrm{resp}}(L)-D \tilde{L} & =(D+a)(1-L)-q_{\mathrm{L}}(L) \\ & =0\end{aligned}$

We now consider the transient dynamics of $L$ when steady state is perturbed by stopping the flow $(D=0)$ and subsequently supplying a pulse of limiting substrate. After stopping the substrate feed, the culture approaches quasi-steady-state starvation conditions, when $\mathrm{d} s / \mathrm{d} t \approx$ $0, q_{\mathrm{s}} \approx 0, \mu \approx 0$, and turnover becomes the main source of $L$ :

$\frac{\mathrm{d} L}{\mathrm{~d} t} \approx a-\Theta q_{\mathrm{resp}}^{\prime}$

If we assume steady-state with respect to $L$ then

$a \approx \Theta q_{\text {resp }}^{\prime}$

i.e. the respiration of the starving population is proportional to the specific turnover rate, $a$.

Addition of a single pulse of limiting substrate results in an instant increase of $s$ from $s \approx 0$ to some positive value $s(0)$. If the substrate pulse is small, $s(0) \ll x / Y$, and we may neglect microbial biomass increase, as well as dilution of $L$ due to cell growth (i.e. $\mu L \approx 0$ ). Taking into account the insignificant contribution of $L$ to the cell carbon budget $(L \ll 1)$ then $(1-L) \approx 1$. Under these simplifying assumptions, the transient dynamics of $L$ can be described by the following form of eqn (10):

$\frac{\mathrm{d} L}{\mathrm{~d} t} \approx q_{\mathrm{s}}-\Theta q_{\mathrm{resp}}+a$

Integration of eqn (14) and substitution for $a$ from eqn (13) gives the algebraic equation:

$\Delta L(t)=L(t)-\tilde{L}=\frac{\Delta s(t)-\Theta\left[\Delta p(t)-\Delta p^{\prime}(t)\right]}{x}$

where $\Delta L(t)=L(t)-\tilde{L}$ is the intracellular substrate concentration in excess of the quasi-steady-state starvation value $\tilde{L}, \Delta s(t)$ is substrate consumed, $\Delta p(t)$ is the total amount of $\mathrm{CO}_{2}$ produced during the transient, and $\Delta p^{\prime}(t)$ is the $\mathrm{CO}_{2}$ produced from endogenous respiration.

The values of $\Delta s(t), \Delta p(t)$ and $\Delta p^{\prime}(t)$ could be determined directly from starvation-enrichment experiments by recording, respectively, added substrate consumption and $\mathrm{CO}_{2}$ evolution before and after substrate addition. However, as a measure of fast respiration kinetics, uptake of dissolved $\mathrm{O}_{2}$ is technically easier to determine than $\mathrm{CO}_{2}$ evolution, because of the shorter response time of $\mathrm{O}_{2}$ electrodes and the absence of complications connected with carbonate formation in liquid. Conversion of $\Delta o$ to $\Delta p$ is straightforward

$\Delta p=\Delta o R Q$ and $\Delta p^{\prime}=\Delta o^{\prime} R Q$

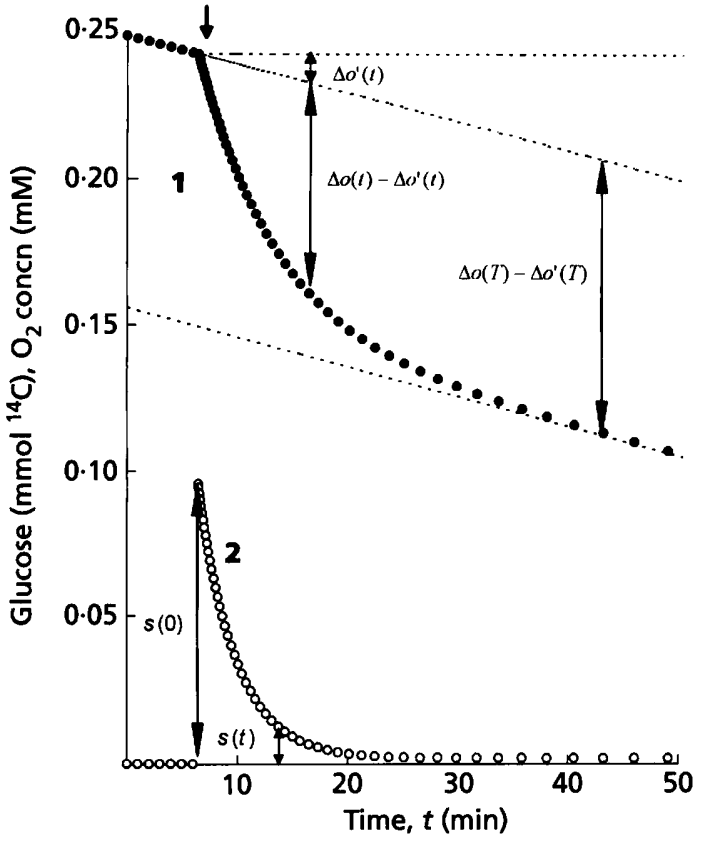

Fig. 2. Illustration of $\Delta L$ determination by the dynamic-balance method from data on $\mathrm{O}_{2}$ (1) and glucose (2) uptake during short-term starvation-enrichment experiments. At time $t=0$, bacterial suspension was transferred to a Clark cell for recording dissolved oxygen concentration. At the time marked by the arrow, glucose $\left(2 \mathrm{mg} \mathrm{l}^{-1}\right)$ was added. Time $t=T$ corresponds to exhaustion of glucose.

where $R Q$ is a respiratory quotient, assumed to be constant.

The stoichiometric parameter $\Theta$ can be determined from the same experiment at an end-point time $t=T$, when both added exosubstrate and intracellular pool are practically exhausted $[\Delta s(T) \approx s(0), \Delta L(T) \approx 0]$. Then it follows from eqns (15) and (16) that:

$\Theta=\frac{s(0)}{\Delta p(t)-\Delta p^{\prime}(T)}=\frac{s(0)}{R Q\left[\Delta o(T)-\Delta o^{\prime}(T)\right]}$

Combining eqns (15)-(17) results in the final expression for $\Delta L$

$\Delta L=\frac{s(0)}{x}\left(1-\frac{\Delta o(t)-\Delta o^{\prime}(t)}{\Delta o(T)-\Delta o^{\prime}(T)}-\frac{s(t)}{s(0)}\right)$

Fig. 2 illustrates the experimental procedure and shows how $\Delta L$ values were found from measured $\mathrm{O}_{2}$ and substrate uptake in starvation-enrichment experiments. The procedure termed the dynamic-balance method was compared with traditional chemical determination of pool sizes.

\section{METHODS}

Organisms and growth medium. Pseudomonas fluorescens VCM-1472 (obtained from the All-Russian Microbial Culture Collection, Moscow) was grown on synthetic medium with glucose as a limiting substrate. The medium contained (in 
$\left.\mathrm{g} \mathrm{l}^{-1}\right): \mathrm{KH}_{2} \mathrm{PO}_{4}, 6 \cdot 7 ; \mathrm{K}_{2} \mathrm{HPO}_{4} .3 \mathrm{H}_{2} \mathrm{O}, 4 \cdot 0 ;\left(\mathrm{NH}_{4}\right)_{2} \mathrm{HPO}_{4}, 1 \cdot 0$; $\mathrm{MgSO}_{4} .7 \mathrm{H}_{2} \mathrm{O}, 0.4 ; \mathrm{CaCl}_{2} .2 \mathrm{H}_{2} \mathrm{O}, 0.08$; glucose, 2.0 ; and micronutrient solution $\left(\mathrm{mg} \mathrm{l}^{-1}\right): \mathrm{CuSO}_{4} .5 \mathrm{H}_{2} \mathrm{O}, 0 \cdot 08 ; \mathrm{KI}, 0 \cdot 2$; $\mathrm{FeCl}_{3} .6 \mathrm{H}_{2} \mathrm{O}, 1 \cdot 0 ; \mathrm{MnSO}_{4} .4 \mathrm{H}_{2} \mathrm{O}, 0 \cdot 8 ; \mathrm{Na}_{2} \mathrm{MoO}_{4} .2 \mathrm{H}_{2} \mathrm{O}, 0 \cdot 4$; $\mathrm{ZnSO}_{4} .7 \mathrm{H}_{2} \mathrm{O}, 0 \cdot 8 ; \mathrm{Na}_{2} \mathrm{~B}_{4} \mathrm{O}_{7} .10 \mathrm{H}_{2} \mathrm{O}, 1 \cdot 0 ; \mathrm{Na}$ EDTA, $10 \cdot 0$.

Chemostat cultures were maintained at $25^{\circ} \mathrm{C}$ and a dilution rate of $0.08 \mathrm{~h}^{-1}\left(\mu_{\mathrm{m}}=0.5 \mathrm{~h}^{-1}\right)$ in a simple continuous-flow apparatus similar to that described by Pirt \& Pirt (1977) except that illumination was omitted. The $\mathrm{pH}$ of the culture remained in the range $6.0-6.4$ without instrumental control. Steady states were considered to be achieved when $\mathrm{OD}_{410}$ was constant after replacement of 5 culture volumes. Respiration rates were estimated from the increase in $\mathrm{CO}_{2}$ concentration in outflowing air as compared with the inflowing air stream $\left(p-p_{0}\right): q_{\text {resp }} x=\left(p-p_{0}\right) F$. The air flow rate through the fermenter, $F$, was measured by a rotameter, and $\mathrm{CO}_{2}$ was analysed by GC (see below). To calculate respiration rates with respect to $\mathrm{O}_{2}$ uptake, we used a value of $R Q=1.12$ (Panikov, 1991).

Determination of $L$ and $\Delta L$ by the dynamic-balance method in starvation-enrichment experiments. Liquid samples from steady-state chemostat cultures were transferred to a $1 \mathrm{~cm}^{3}$ temperature-controlled cell for measurement of dissolved oxygen uptake using a Clark-type electrode. During the first $20 \mathrm{~min}$ after sampling, endogenous respiration rate was recorded; then $10 \mu$ l glucose solution was added to give a final concentration of $5 \mathrm{mg} \mathrm{l}^{-1}\left(2 \mathrm{mg} \mathrm{C} \mathrm{I}^{-1}\right)$. Measurement was continued until the respiration rate approached the former endogenous level (usually after $15-30 \mathrm{~min}$ ). To follow the dynamics of substrate consumption, similar short-term experiments were run, with three modifications: $\left[\mathrm{U}-{ }^{14} \mathrm{C}\right]$ glucose was employed (specific radioactivity $0.28 \mathrm{Ci} \mathrm{mmol}^{-1}, 10.36 \mathrm{GBq}$ $\mathrm{mmol}^{-1}$ ), the volume of sample taken from the chemostat was increased to $10 \mathrm{~cm}^{3}$, and incubation was carried out in a $20 \mathrm{~cm}^{3}$ temperature-controlled, stoppered glass vessel with a magnetic stirrer. At timed intervals after $\left[{ }^{14} \mathrm{C}\right]$ glucose addition, $0 \cdot 1 \mathrm{~cm}^{3}$ samples were analysed for residual substrate (glucose) and extracellular metabolites by measuring radioactivity in the filtrate after filtration through $0.2 \mu \mathrm{m}$ Synpor filters.

To study the effect of cell density, we used bacterial suspensions from the same chemostat culture diluted 2-10fold.

Determination of pool size by the ${ }^{14} \mathrm{C}$ isotope technique. We used two types of biomass labelling: (i) uniform and (ii) with predominant labelling of 'mobile' cell components.

Uniform labelling was achieved in chemostat culture with [U$\left.{ }^{14} \mathrm{C}\right]$ glucose in the medium feed: the $s_{\mathrm{r}}$ value was $1.0 \mathrm{~g} \mathrm{l}^{-1}$ and total radioactivity $165 \mathrm{~Bq} \mathrm{~cm}^{-3}$. Other conditions were similar to those described above. Pool sizes were determined in steady-state chemostat cultures and during starvation $8 \mathrm{~h}$ after stopping the substate flow. Concurrently, respiration activity was measured with a Clark electrode.

The intracellular content of low-molecular-mass substances (the $\mathrm{L}$ pool or 'TCA pool') was determined in cold trichloracetic acid (TCA) extracts. Culture samples $\left(2 \mathrm{~cm}^{3}\right)$ were filtered through membrane filters (Synpor, $0.2 \mu \mathrm{m}$ ); precipitates were washed twice using the mineral base of the nutrient medium and then extracted for $10 \mathrm{~min}$ with $2 \mathrm{~cm}^{3}$ $10 \%$ cold TCA at $1{ }^{\circ} \mathrm{C}$ with constant agitation. Radioactivity was measured in $0 \cdot 1 \mathrm{~cm}^{3}$ of the filtrates using the washing solution as a blank and a mixture of $10 \%$ TCA with $\left[{ }^{14} \mathrm{C}\right]$ glucose as a standard. The sampling time from the start of cell transfer to the addition of TCA was $1 \cdot 5-2 \cdot 0 \mathrm{~min}$.
To achieve predominant labelling of 'mobile' cell components, unlabelled cells were starved ( $L$ tends to $\tilde{L} \approx 0$ ) and then presented with an amount of $\left[{ }^{14} \mathrm{C}\right]$ glucose sufficient to replace about $20 \%$ of unlabelled cell carbon. Samples $\left(20 \mathrm{~cm}^{3}\right)$ of bacterial suspension $\left(x=344 \mathrm{mg} \mathrm{Cl}^{-1}\right)$ were transferred from the chemostat to $500 \mathrm{~cm}^{3}$ serum bottles and incubated on a shaker at $25^{\circ} \mathrm{C}$ and 180 r.p.m. for $25 \mathrm{~min}$. Then $\left[\mathrm{U}-{ }^{14} \mathrm{C}\right]$ glucose was added to a final concentration of $200 \mathrm{mg} \mathrm{l}^{-1}$ or $80 \mathrm{mg} \mathrm{Cl}^{-1}$ (final activity $1.05 \mu \mathrm{Ci} \mathrm{cm}^{-3}$, $\left.38.85 \mathrm{kBq} \mathrm{cm}^{-3}\right)$. Samples from the headspace and the culture liquid were withdrawn by syringe through a serum cap and radioactivity in the following fractions was analysed: $\mathrm{CO}_{2}$, cells, cold TCA extract (L pool) and cell-free culture fluid (residual substrate + extracellular metabolites). In a parallel run, the bacterial biomass and total $\mathrm{CO}_{2}$ content were determined.

Analytical techniques. The radioactivity in solutions was measured in $0.1 \mathrm{~cm}^{3}$ samples plus $2.5 \mathrm{~cm}^{3}$ GC-8 scintillation cocktail in an Ultrabeta scintillation counter (LKB Vallac). The content of ${ }^{14} \mathrm{C}$ in the bacterial biomass was estimated from the difference between the total radioactivity of the suspension and the filtrate.

${ }^{14} \mathrm{CO}_{2}$ was determined in $2 \mathrm{~cm}^{3}$ gas samples which were injected into stoppered flasks containing $2.5 \mathrm{~cm}^{3}$ absorbing liquid $(\alpha$-phenylethylamine/ethanol/GC-106 scintillation cocktail, = $1: 1: 3$, by vol.). Radioactivity was measured after $30 \mathrm{~min}$ incubation. The amount of $\mathrm{CO}_{2}$ absorbed was determined by gas chromatography (GC).

Total $\mathrm{CO}_{2}$ was determined by $\mathrm{GC}$ using an instrument with a thermoconductivity detector. At the end of each experiment, the culture fluid was acidified with $\mathrm{HCl}$ to $\mathrm{pH} 2.5$ in order to release carbonates. Typically, the $\mathrm{HCO}_{3}^{-}$content did not exceed $1-5 \%$ of the total $\mathrm{CO}_{2}$. When calculating dynamic data, appropriate correction was made for gas and liquid withdrawal during sampling. The biomass was estimated turbidimetrically at $410 \mathrm{~nm}$ and by dichromate oxidation of the bacterial cells, calibration being made by plotting the chromium reduced versus the $\mathrm{C}$ content of the cells obtained with a Carlo Erba CHN analyser (Panikov et al., 1989). Amino acid content was determined in TCA extracts with an automated analyser.

Calculations. These were made with an IBM PC. The parameters of the algebraic equations were determined by multiple linear regression with routines available in Lotus-123 or by non-linear regression (POISK-4) written in PASCAL-6 (Krutko et al., 1988).

\section{RESULTS AND DISCUSSION}

We start with an examination of the dynamic data, major attention being paid to verification of assumptions made in the Introduction.

\section{Dynamics of endogenous respiration}

The terms $q_{\text {resp }}^{\prime}$ and $\Delta o^{\prime}$ are present in many of the equations derived, so they are of considerable importance. Endogenous respiration is defined as that which results from decomposition and oxidation of cell constituents. It could be estimated directly under starvation conditions, when $s \approx 0$. In the present work starvation was induced by arresting substrate feed to chemostat cultures or, equivalently, by transfer of a culture sample from the chemostat to an incubation flask. The dynamics 
of respiration are shown in Fig. 3 for the initial stages of starvation (0-20 min) and in Fig. 4 for longer periods of starvation $(0-8 \mathrm{~h})$. In both cases, respiration rates, $q_{\text {resp }}$, decreased during the first 5-7 min from steady-state chemostat rates of about $6 \mathrm{mmol} \mathrm{O}_{2} \mathrm{~h}^{-1}$ (g biomass C) ${ }^{-1}$ to a constant rate of about $1 \mathrm{mmol} \mathrm{O}_{2} \mathrm{~h}^{-1}$ (g biomass $\mathrm{C})^{-1}$. This constant rate was taken to be the endogenous respiration rate, $q_{\text {resp }}^{\prime}$.

Thus, the following assumptions made in the derivations of eqns (12) and (13) were upheld: (i) under starvation conditions, steady state with respect to $L$ is quickly established, and (ii) endogenous respiration obeys zeroorder kinetics (i.e. $q_{\text {resp }}^{\prime}$ is constant). The transition to starvation (quasi-) steady-state was completed in 5-10 min. Hence, to obtain a reliable estimate of $q_{\text {resp }}^{\prime}$, we chose measurements obtained in the time interval from 15 to $25 \mathrm{~min}$ after the onset of starvation.

\section{Dynamics of respiration and substrate consumption in starvation-enrichment experiments}

Typical experimental results are shown in Fig. 3. Arresting the medium supply resulted in starvation, which has been discussed already. Substrate addition immediately initiated a new burst of bacterial activity. The $\left[{ }^{14} \mathrm{C}\right]$ glucose consumption rate was maximal at the very beginning of enrichment; the concentration of label in the culture filtrate decreased rapidly for 1-2 min and then stabilized at $2 \cdot 5-5 \%$ of $s(0)$. This residual ${ }^{14} \mathrm{C}$ radioactivity was probably due to recalcitrant extracellular metabolites. Respiration increased from the background endogenous level, $q_{\text {resp }}^{\prime}$, to $8-25 \mathrm{mmol} \mathrm{O}_{2}$ $\mathrm{h}^{-1}$ (g biomass $\left.\mathrm{C}\right)^{-1}$ depending on cell density (see below). Respiration was not strongly correlated with substrate uptake; rather, the two processes developed in succession. Maximal rates of respiration lagged behind maximal rates of glucose consumption by approximately $1 \mathrm{~min}$. This time delay gave rise to a transient increase in internal substrate concentration.

At the concentration of substrate amendment utilized $\left.(2 \mathrm{mg} \mathrm{C} \mathrm{l})^{-1}\right)$ no significant changes in biomass $(x=$ $344 \mathrm{mg} \mathrm{Cl}^{-1}$ ) were observed during the course of the experiments. Neither the decrease during starvation nor the increase after glucose addition exceeded $0 \cdot 2-0 \cdot 3 \%$. This is well below the sensitivity of the measuring methods employed. Hence, the assumptions made in deriving eqn $(14)(\mathrm{d} x / \mathrm{d} t \approx 0, \mu L \approx 0)$ can be considered to be appropriate.

The values of the stoichiometric parameter $\Theta$ varied in different individual trials between 2.07 and $2.23 \mathrm{~g} \mathrm{C}$ $\left(\mathrm{g} \mathrm{C}^{-1}\right.$. The mean standard error for $\Theta$ was $2 \cdot 13 \pm 0.05 \mathrm{~g} \mathrm{C}(\mathrm{g} \mathrm{C})^{-1}$. The reliability of this estimate was confirmed by steady-state chemostat data obtained for the related parameter $Y_{\mathrm{s} / \mathrm{p}}$, which had a mean value of $2 \cdot 1 \mathrm{~g}$ glucose- $\mathrm{C}$ consumed $\left(\mathrm{g} \mathrm{CO}_{2}-\mathrm{C}\right)^{-1}$. The relationship between $\Theta$ and $Y_{\mathrm{s} / \mathrm{p}}$ is as follows :

$Y_{\mathrm{s} / \mathrm{p}}=\frac{q_{\mathrm{s}}}{q_{\text {resp }}}=\Theta-\frac{a(1-L)}{q_{\text {resp }}}$ and since $a(1-L) \ll q_{\mathrm{resp}}$, then $\Theta \approx Y_{\mathrm{s} / \mathrm{p}}$. Thus, the stoichiometry of $P$. fluorescens growth was similar under steady-state chemostat conditions and in the short-term starvation-enrichment experiments.

\section{Dependence of respiration rate on cell density}

Bacterial suspensions from chemostat cultures were diluted with culture filtrate to give a series of cell densities from 34 to $344 \mathrm{mg}$ biomass $\mathrm{C}^{-1}$. The physiological state of the cells in these preparations was identical and the initial glucose concentration in the medium was $s(0)=2 \mathrm{mg} \mathrm{Cl}^{-1}$. The total amount of oxygen consumed, $\Delta o^{\prime}$, did not depend on cell density and was almost constant: $63 \cdot 3-68 \cdot 3 \mathrm{mmol} \mathrm{l}^{-1}$. This range corresponded to oxidation of $38-41 \%$ of the added glucose. In contrast, the specific respiration rate $q_{\text {resp }}$ showed an inverse relationship with cell density: diluted suspensions had higher respiration activity. The observed relationship between $q_{\text {resp }}$ and $x$ has a straightforward explanation in that an equivalent amount of exosubstrate, $2 \mathrm{mg} \mathrm{Cl}^{-1}$, was consumed by different amounts of biomass. Thus the more biomass present, the less intracellular substrates, $L$, per cell. The approximate lower limit of $L$ may be calculated as follows. If $x=344 \mathrm{mg} \mathrm{Cl}^{-1}$, then $L=s(0) / x=2 / 344=$ $5.8 \mathrm{mg} \mathrm{C}$ ( $\mathrm{g}$ biomass $\mathrm{C})^{-1}$. The upper limit is attained at the lowest biomass $x=34.4 \mathrm{mg} \mathrm{Cl}^{-1}$; then $L=2$ / $34.4=58.0 \mathrm{mg} \mathrm{C}(\mathrm{g} \text { biomass } \mathrm{C})^{-1}$, or 10 times higher. However, for a more accurate determination of $L$ complete mass balance data are required.

\section{Determination of $\Delta L$ and $L$ by the dynamic-balance method}

The data on $\mathrm{O}_{2}$ and glucose consumption were used to calculate the increase in intracellular pool sizes $\Delta L$, according to eqn (18). $\Delta L$ dynamics were described by a curve with one maximum and were closely related to respiration activity (compare curves 3 and 4 in Fig. 3).

To study further the relationship between respiration rate and pool size, we used data from five independent starvation-enrichment experiments employing different cell densities. In Fig. 5 these data are plotted as specific rates of $\mathrm{O}_{2}$ uptake, $q_{\text {resp }}$, against corresponding $\Delta L$ values. The functional relationship $q_{\text {resp }}=f(\Delta L)$ was hyperbolic. However, the Michaelis-Menten-type hyperbola was shifted to the left along the $\Delta L$ axes from 0 to $-\hat{L}$. Formally, the relationship can be expressed by the following modification of the Michaelis-Menten equation:

$q_{\text {resp }}=\frac{Q_{\text {resp }}(\hat{L}+\Delta L)}{K_{\mathrm{L}}+\hat{L}+\Delta L}$

where $Q_{\text {resp }}$ is the maximal respiration rate, $K_{\mathrm{L}}$ is the saturation constant and $\hat{L}$ is the internal substrate concentration just before glucose addition in starvationenrichment experiments. With bacteria of identical physiological state, the $\hat{L}$ values should be similar for all points plotted in Fig. 5 . Hence, $\hat{L}$ may be treated as a 

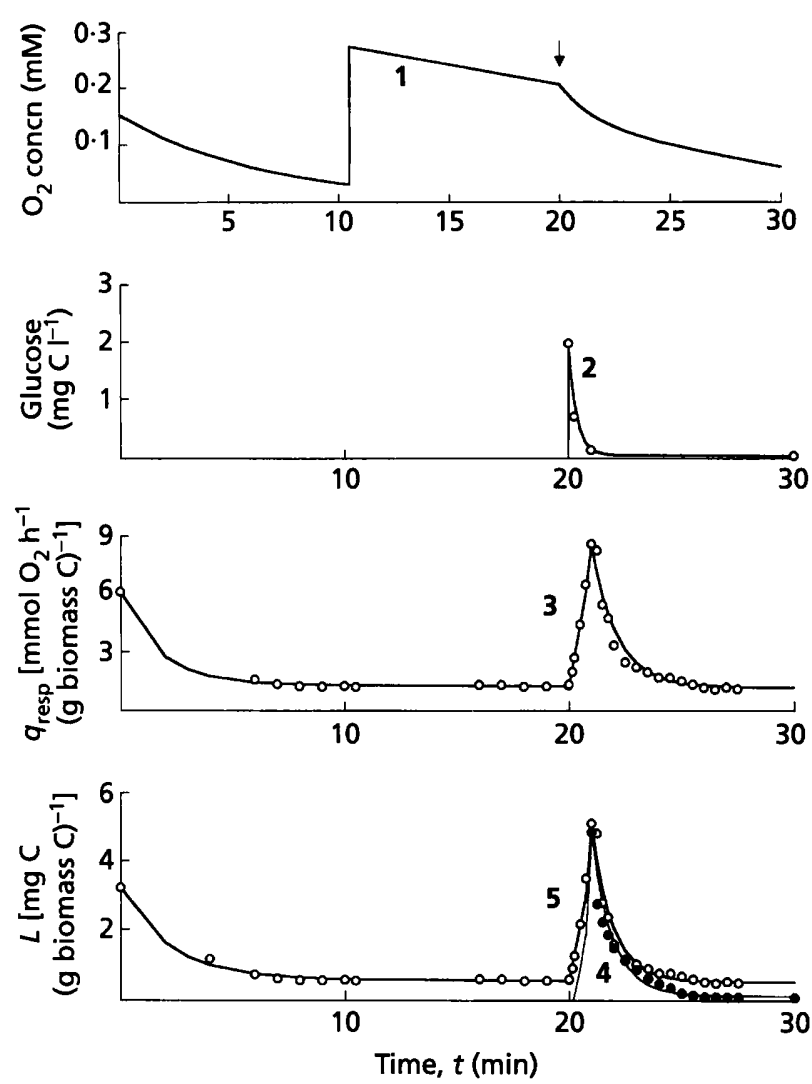

Fig. 3. Dynamics of the starvation-enrichment experiment used for determining $\Delta L$ by the dynamic-balance method. Bacterial suspension was withdrawn from a chemostat culture at $t=0$, and at the time indicated by the arrow, $\left[{ }^{14} \mathrm{C}\right]$ glucose $\left(2 \mathrm{mg} \mathrm{l}^{-1}\right)$ was added. The following variables were recorded: 1 , dissolved oxygen concentration by Clark electrode; 2 , residual ${ }^{14} \mathrm{C}$ glucose and extracellular metabolites in the culture filtrate; 3 , specific $\mathrm{O}_{2}$ uptake rate; 4 , increase of pool, $\Delta L$, during substrate enrichment (calculated from C-balance according to eqn 18); 5 the total intracellular concentration of oxidizable substrate, calculated from eqn 21 .

parameter and found by best-fit non-linear regression along with $Q_{\text {resp }}$ and $K_{\mathrm{L}}$. Such determination gave the following numeric values: $\hat{L}=0.54 \mathrm{mg} \mathrm{C}$ (g biomass $\mathrm{C})^{-1}, K_{\mathrm{L}}=12 \cdot 1 \mathrm{mg} \mathrm{C}(\mathrm{g} \text { biomass } \mathrm{C})^{-1}$, and $Q_{\text {resp }}=$ $29 \cdot 1 \mathrm{mmol} \mathrm{O}_{2} \mathrm{~h}^{-1}$ (g biomass C) ${ }^{-1}$.

To examine the possible cooperative effects in intracellular reactions we attempted to fit the experimental data to a modified Hill equation:

$q_{\text {resp }}=\frac{Q_{\text {resp }}(\hat{L}+\Delta L)^{n}}{K_{\mathrm{L}}^{n}+(L+\Delta L)^{n}}$

where $n$ is a measure of cooperativity (positive at $n>1$, and negative at $n<1)$. However, non-linear regression gave a value of $n=1 \cdot 08$, which does not differ significantly from unity. Moreover, the use of more complicated forms of eqn (21) did not improve the goodness of fit ; the sum of square residuals was 97.97 for eqn (20) and $97 \cdot 77$ for eqn (21). Thus eqn (20) is preferred as it is simpler.

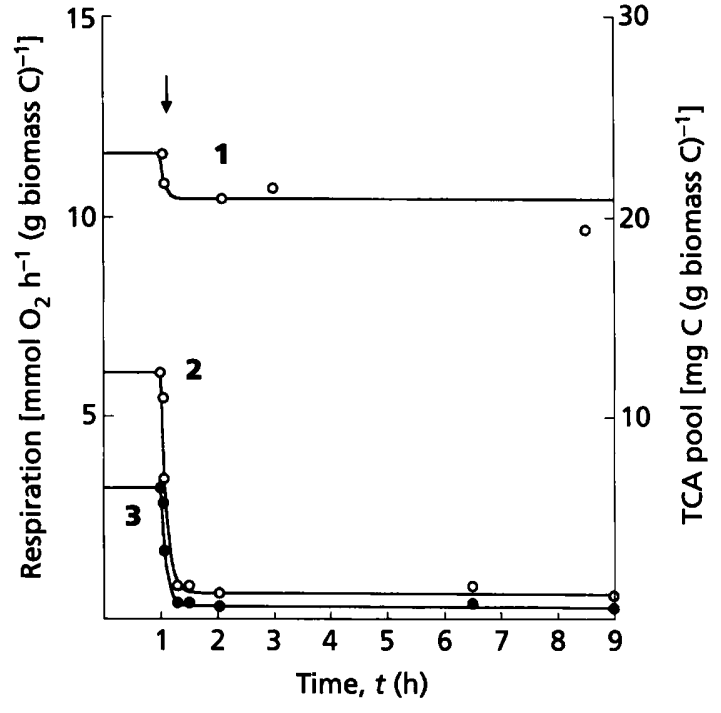

Fig. 4. Dynamics of the TCA pool (1), respiration (2) and $L$ values determined by the dynamic-balance method (3), in chemostat culture of $\boldsymbol{P}$. fluorescens before and after stopping the substrate feed (arrow). The chemostat culture was maintained at $D=0.088 \mathrm{~h}^{-1}$ with $\left[{ }^{14} \mathrm{C}\right]$ glucose in the input medium.

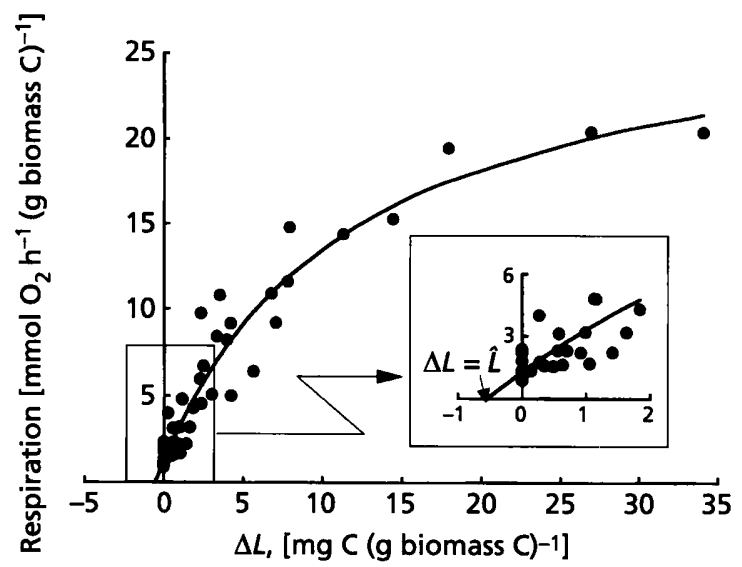

Fig. 5. Relationship between specific $\mathrm{O}_{2}$ uptake rate and $\Delta \mathrm{L}$. Experimental data were obtained from the starvationenrichment results illustrated in Fig. 3. The curve is calculated according to eqn (20). The inset illustrates extrapolation of the curve to negative values of $\Delta L$, giving an estimation of the pool size of starving cells before glucose addition, $\hat{L}$.

The Michaelis-Menten equation may also be used for resolving the inverse problem, i.e. how to calculate $L$ from respiration rate. By introducing the term of total intracellular substrate concentration $L=\hat{L}+\Delta L$ we obtain, from eqn (20):

$L=\hat{L}+\Delta L=\frac{q_{\text {resp }} K_{L}}{Q_{\text {resp }}-q_{\text {resp }}}$

This expression enables instantaneous determination of pool sizes, provided the parameters $Q_{\text {resp }}$ and $K_{\mathrm{L}}$ are 

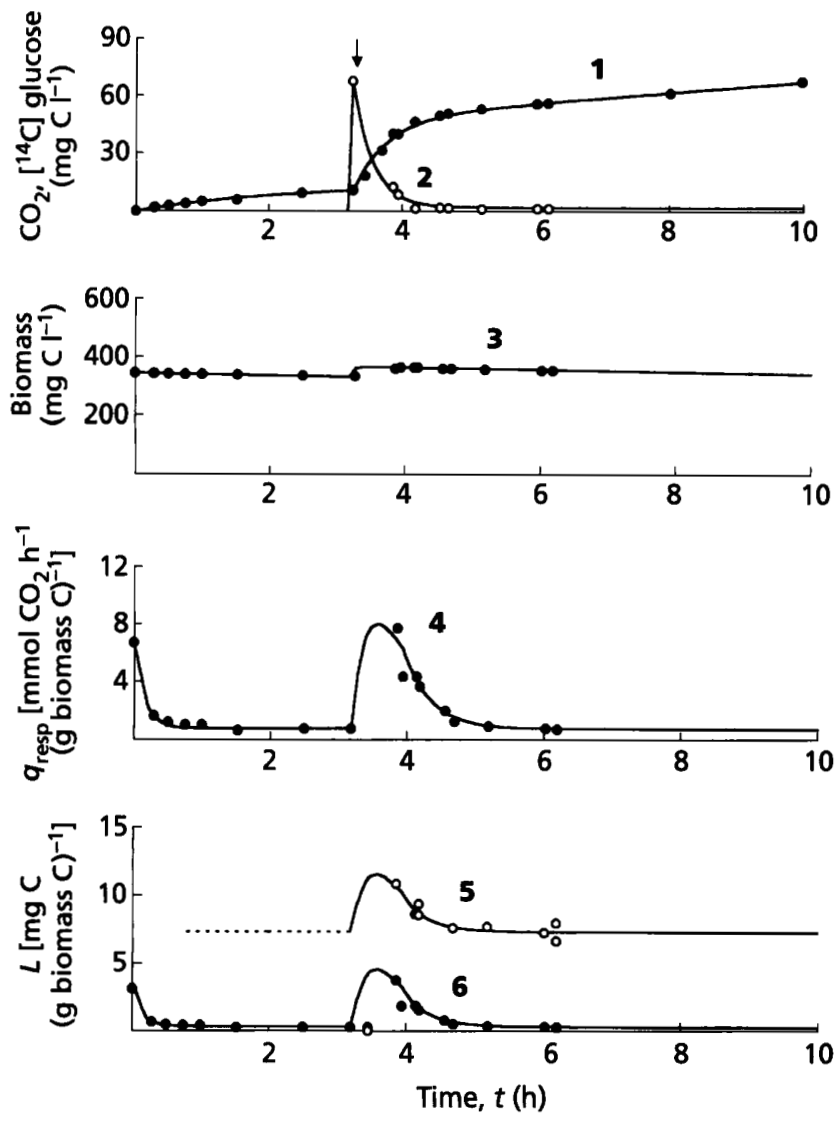

Fig. 6. Dynamics of non-uniform labelling of bacterial biomass by $\left[{ }^{14} \mathrm{C}\right]$ glucose. Bacterial suspension was withdrawn from a chemostat culture at $t=0$, then at the time indicated by the arrow, $\left[{ }^{14} \mathrm{C}\right]$ glucose $\left(70 \mathrm{mg} \mathrm{I}^{-1}\right)$ was added. The following variables were recorded: total amount of $\mathrm{CO}_{2}$ in the flask headspace, determined by GC (1); residual ${ }^{14} \mathrm{C}$ glucose and extracellular metabolites in the culture filtrate (2); total bacterial biomass (3); specific respiration rate $(4) ;{ }^{14} \mathrm{C}$ content in cold TCA extract (5); total intracellular concentration of oxidizable substrate, calculated from (4) with $R Q=1.12$ according to eqn (22) (6).

known. The dynamics of the $L$-pool calculated from respiration rates according to eqn (22) are plotted in Fig. 3 as curve 5 . Under steady-state chemostat conditions at $D=0.08 \mathrm{~h}^{-1}$, the $\tilde{L}$ value was $3.2 \mathrm{mg} \mathrm{C}(\mathrm{g} \text { biomass } \mathrm{C})^{-1}$. The highest observed value was $35 \mathrm{mg} \mathrm{C}$ ( $\mathrm{g}$ biomass C) $^{-1}$. Thus, our last assumption made in the theoretical introduction, $(1-\tilde{L}) \approx 1$, could be considered as reasonable, because the term $(1-\tilde{L})$ never decreased below $0 \cdot 96$.

\section{Comparison of kinetic and direct chemical methods of $L$ determination}

Direct determinations of ${ }^{14} \mathrm{C}$ content in cold TCA extracts (TCA pool) were made in two experiments: (i) with uniformly labelled cells (Fig. 4), and (ii) with only mobile cell components labelled (Fig. 6).

In the first experiment, we compared the TCA pool with determinations made by the dynamic-balance method during transition from steady-state growth to starvation. Steady-state TCA pool concentrations were established at $23.2 \mathrm{mg} \mathrm{C}(\mathrm{g} \text { biomass } \mathrm{C})^{-1}$. The amino acid content of the TCA pool accounted for $3 \pm 1 \mathrm{mg} \mathrm{C}$ ( $\mathrm{g}$ biomass $\mathrm{C})^{-1}$, close to the results obtained by Tempest et al. (1970) using chemostat cultures of other Gram-negative bacteria. After the substrate feed was switched off, the TCA pool rapidly decreased to $21 \mathrm{mg} \mathrm{C}$ ( $\mathrm{g}$ biomass $\mathrm{C})^{-1}$ and then remained almost constant. Detectable decreases in pool sizes were observed only after long periods of starvation. Hence, the TCA pool consists of variable and stable fractions, the former being no more than $10 \%$ of the total TCA pool.

$L$ determinations by the dynamic-balance method showed dynamics similar to those of the variable fraction of the TCA pool. Immediately after starvation, the $L$ value fell from the chemostat steady-state value of $3.2 \mathrm{mg} \mathrm{C}$ ( $\mathrm{g}$ biomass $\mathrm{C})^{-1}$ to the starvation background level of $0.4-0.5 \mathrm{mg} \mathrm{C}$ ( $\mathrm{g}$ biomass $\mathrm{C})^{-1}$. From these data we may draw the conclusion that cold TCA extracts not only the respiratory cell substrates but also some relatively inert cell components. We did not attempt to analyse these, but they may originate from hydrolysed polymeric cell components.

In the second experiment we followed the dynamics of the TCA pool and other components of the cell carbon budget after addition of a rather large pulse of $\left[{ }^{14} \mathrm{C}\right]$ glucose to starving bacteria (Fig. 6). In this case it was expected that the ${ }^{14} \mathrm{C}$ label would replace the entire pool of low-molecular-mass intermediates and only part of the total cell carbon located, say, in proteins, nucleic acids and cell wall components with a short turnover time. The dynamics of $\left[{ }^{14} \mathrm{C}\right]$ glucose consumption, ${ }^{14} \mathrm{CO}_{2}$ evolution and respiration were similar to those observed after a small pulse of glucose (compare Fig. 6 and Fig. 3). The differences were only quantitative; the duration of substrate-induced respiration increased from $5 \mathrm{~min}$ to $2 \mathrm{~h}$, and amount of biomass increased by about $10 \%$. The uptake of $\left[{ }^{14} \mathrm{C}\right]$ glucose led to formation of a TCA pool of $11 \mathrm{mg} \mathrm{C}$ ( $\mathrm{g}$ biomass $\mathrm{C}^{-1}$ which then decreased to the constant starvation level of $7 \mathrm{mgC}$ ( $\mathrm{g}$ biomass $\mathrm{C}^{-1}$. Again formation of variable and invariable (stable) TCA pool fractions was observed. However, with this type of labelling the variable fraction accounted for as much as $36 \%$ of the total labelled TCA pool as compared with $10 \%$ in the first experiment. Again, $L$ concentrations determined by the dynamicbalance method correlated well with the size of the variable TCA pool; both values accounted for $4 \mathrm{mg} \mathrm{C}$ ( $\mathrm{g}$ biomass $\mathrm{C})^{-1}$ at maximal respiration activity.

The simplest explanation of the TCA-pool dynamics observed in both experiments is that the stable fraction is an artifact resulting from treatment of the cells with cold TCA. The source of the stable fraction may be acidsensitive polymeric substances, which are normally part of structural cell components. This explanation may be formalized in terms of the growth scheme (see Fig. 1) as follows:

$\underset{{ }^{14} \mathrm{C} \text { in TCA extract }}{\mathrm{TCA} \text { pool }}=\underset{\text { Variable fraction }}{\lambda_{1} L}+\underset{\text { Invariable fraction }}{\lambda_{2} \kappa X^{\prime}}$ 
where $L$ is the actual pool of low-molecular-mass intermediates, $X^{\prime}$ represents polymeric cell components, and $\kappa X^{\prime}$ is the fraction of acid-sensitive macromolecules. The terms $\lambda_{1}$ and $\lambda_{2}$ denote ${ }^{14} \mathrm{C}$ isotopic enrichment (relative to standard) of cell pool and polymeric cell components, respectively. We may put $\lambda_{1}=1$ for both experiments, neglecting very small isotope fractionation effects in respect of ${ }^{14} \mathrm{C}$. For the first experiment with uniform biomass labelling, the coefficient $\lambda_{2}$ is also equal to unity, while $\lambda_{2}$ may be roughly estimated from the proportion $\lambda_{2}={ }^{14} \mathrm{C}$ uptake/total biomass $\mathrm{C} \approx 0 \cdot 1$. The best fit to experimental data (Figs 3 and 6) provides $\kappa$ values of 0.06 for the first experiment and 0.18 for the second. Thus $6 \%$ (uniform labelling) to $18 \%$ (mobile fraction labelling) of polymeric cell components could be extracted by cold TCA and erroneously regarded as pool components.

\section{Conclusions}

We have described a simple and accurate kinetic technique for determining the pool size of readily oxidizable intracellular compounds. It is based on shortterm starvation-enrichment experiments and application of carbon mass balance equations. The net pool change $(\Delta L)$ is simply the difference between carbon uptake and carbon respired. The dynamics of specific respiration rate, $q_{\text {resp }}$, in the course of experiments was related to $\Delta L$ according to a modified Michaelis-Menten equation which contains an identifiable parameter, $\hat{L}$, the pool size before substrate amendment. Pool sizes depended on the concentration of glucose supplied to the cells and varied between 0.4 and $35 \mathrm{mg} \mathrm{C}$ (g biomass $\mathrm{C})^{-1}$.

Direct chemical determination of $L$ confirmed the validity of the technique. We identified two fractions of cell constituents in cold TCA extracts. The first fraction was variable and was closely correlated with both respiration and $L$ values determined by the kinetic technique. The second, invariable, 'stable' fraction did not show a relation with respiration dynamics and probably resulted from TCA degradation of polymeric cell components.

Using the starvation-enrichment technique, we found that the relationship between pool size and respiration obeyed simple Michaelis-Menten kinetics. This implies that the Michaelis constant $\left(K_{\mathrm{m}}\right)$ for numerous individual metabolic reactions must be of similar order of magnitude, close to the mean value we obtained

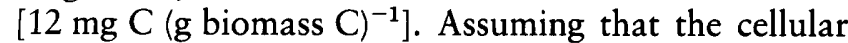
water content is $90 \%$ and that typical intracellular substrates have an average of six carbon atoms, then the $K_{\mathrm{m}}$ is about $8.3 \mathrm{mM}$, close to the mean value reported for pure enzymes (Varfolomeyev, 1987).

The technique has some limitations. It cannot be applied to carbon- and energy-sufficient cultures because they do not respond to short-term starvation or substrate enrichment. However, it should be of particular value for studying substrate-limited growth and for identi- fying parameters and variables associated with structured models.

\section{ACKNOWLEDGEMENTS}

We thank the Royal Society of London and the North Atlantic Treaty Organization for grants enabling us to undertake this cooperative research. The participation of A.G.D. and N.S.P. was also made possible in part by Grant no. MIQ 000 from the International Science Foundation and Grant no. 96-04-49321 of the Russian Fund for Fundamental Research.

\section{REFERENCES}

Domach, M. M., Leung, S. K., Cahn, R. E., Cacks, G. G. \& Shuler, M. L. (1984). Computer model for glucose-limited growth of single cell of Escherichia coli B/r-A. Biotechnol Bioeng 26, 203-216.

Dorofeyev, A. G. \& Panikov, N. S. (1992). A quantitative description of microorganism growth in a batch culture depending on the physiologial state of the inoculate. Microbiology (English translation of Mikrobiologiya) 60, 448-455.

Fredrickson, A. G. (1976). Formulation of structured growth models. Biotechnol Bioeng 18, 1481-1486.

Guthke, R. \& Knorre, W. A. (1980). Oscillatory and multistability behavior in continuous culture models: the S-P-X model. In Continuous Cultivation of Micro-organisms, Proceedings of the 7th Symposium, Prague, 10-14 July 1978, pp. 207-214. Edited by B. Sikyta, Z. Fencl \& V. Polacek. Prague: Czechoslovak Academy of Sciences.

Herbert, D. (1958). Some principles of continuous culture. In Recent Progress in Microbiology (VII International Congress for Microbiology), pp. 381-396. Edited by G. Tunevall. Stockholm: Almquist \& Wiksell.

lerusalimsky, N. D. (1967). Bottle-necks in metabolism as growth rate controlling factors. In Microbial Physiology and Continuous Culture, pp. 23-33. Edited by E. O. Powell, C. G. T. Evans, R. E. Strange \& D. W. Tempest. Salisbury: HMSO.

Jeong, J. W., Snay, J. \& Ataai, M. M. (1990). A mathematical model for examining growth and sporulation processes of Bacillus subtilis. Biotechnol Bioeng 35, 160-184.

Krutko, P. D., Maximov, A. I. \& Skwortzov, L. M. (1988). Algorithms and Computer Programs in Designing of Automatic Systems. Moscow: Radyo y Svyaz (in Russian).

Monod, J. (1942). Recherches sur la Croissance des Cultures Bactériennes. Paris: Hermann.

Monod, J. (1950). La technique de culture continue: théorie et applications. Ann Inst Pasteur 79, 390-410.

Nyholm, N. (1976). A mathematical model for microbial growth under limitation by conservative substrates. Biotechnol Bioeng 18, 1043-1056.

Panikov, N. S. (1991). A synthetic chemostat model as a tool for description of complex dynamic behavior of microorganisms. Microbiology (English translation of Mikrobiologiya) 60, 431-441.

Pannikov, N. S. (1995). Microbial Growth Kinetics. London \& Glasgow: Chapman \& Hall.

Panikov, N. S., Shekhovtsova, N. V., Dorofeyev, A. G. \& Zvyagintsev, D. G. (1989). Quantitative investigation of the dynamics of death in starving microorganisms. Microbiology (English translation of Mikrobiologiya) 57, 786-794. 
Pirt, S. J. (1975). Principles of Microbe and Cell Cultivation. Oxford: Blackwell Scientific Publications.

Pirt, W. M. \& Pirt, S. J. (1977). Photosynthetic production of biomass and starch by Chlorella in chemostat culture. J Appl Chem Biotechnol 27, 643-650.

Powell, E. O. (1967). The growth rate of microorganisms as a function of substrate concentration. In Microbial Physiology and Continuous Culture, pp. 34-56. Edited by E. O. Powell, C. G. T. Evans, R. E. Strange \& D. W. Tempest. Salisbury: HMSO.

Powell, E. O. (1969). Transient changes in the growth rate of micoorganisms. In Continuous Cultivation of Microorganisms, pp. 275-284. Edited by I. Malek, K. Beran, Z. Fencl, V. Munk, J. Ricica \& H. Smrckova. New York: Academic Press.

Tempest, D. W., Meers, J. L. \& Brown, C. M. (1970). Influence of environment on the content and composition of microbial free amino acid pools. J Gen Microbiol 64, 171-185.

Varfolomeyev, S. D. (1987). The kinetic principles of microbial populations development. In Modern Problems of Biokinetics, pp. 6-77. Moscow: Moscow University Publications (in Russian).

Received 17 July 1996; revised 15 December 1996; accepted 14 January 1997. 